\title{
SUBVENÇÃO ECONÔMICA E FOMENTO À INOVAÇÃO: ANÁLISE DA TRANSPARÊNCIA E DA ACESSIBILIDADE À INFORMAÇÃO DO PROGRAMA TECNOVA NOS ESTADOS DA REGIÃO SUL
}

Amanda Cristina De Castro ${ }^{1}$

Giovani Cruzara ${ }^{1}$

Ana Paula Cherobim ${ }^{1}$

José Roberto Frega ${ }^{1}$

${ }^{1}$ Universidade Federal do Paraná 


\section{Subvenção Econômica e Fomento à Inovação: análise da}

\section{transparência e da acessibilidade à informação do Programa \\ Tecnova nos estados da região Sul}

\section{Resumo:}

O objetivo deste estudo é analisar a transparência e a acessibilidade à informação do Programa Tecnova nos estados da região sul. Para tal, utilizou dados de relatórios, documentos públicos e informações disponibilizados pelos órgãos executores dos três estados. Foram comparadas transparência e acessibilidade à informação, distribuídas nos quesitos: estrutura de governança; edital de abertura; resultados alcançados; divulgação e acompanhamento dos gastos governamentais; qualidade técnica destas informações em relação ao que e como tais informações foram divulgadas; e facilidade no acesso as informações. A abordagem metodológica é qualitativa, por meio da análise de conteúdo. Os resultados encontrados mostram maior transparência e facilidade de acesso no programa no Paraná, seguido pelo Rio Grande do Sul. Quanto aos resultados alcançados, Paraná e Rio Grande do Sul apresentam detalhadamente os resultados de curto prazo, em relatórios e eventos, sem contudo, abordar questões de desempenho ou de impactos para a sociedade em geral.

Palavras-chave: Financiamento a inovação. Subvenção Econômica. Transparência. Acessibilidade à informação.

\section{Introdução}

A inovação é um fator chave para a competitividade das empresas e por consequência é considerada a impulsão para alcançar o desenvolvimento econômico (PEREZ, 2012; CARRIJO; BOTELHO, 2013; BUENO; TORKOMIAN, 2014). Assim, para as empresas sobreviverem no longo prazo, além de serem competitiva em custo, devem fazer o uso de inovação tecnológica, de modo a aplicar seus conhecimentos para produzir e comercializar melhores produtos e processos à seus clientes (ANDREASSI; SIQUEIRA, 2006), assim obtendo uma vantagem estratégica.

Contudo, para inovar é necessário que existam investimentos. As micro e pequenas empresas, em especial, tem o desafio é ainda maior, pois a maioria (82\%) delas enfrentam dificuldades para obter empréstimos, em razão, principalmente, dos juros altos e da falta de garantias, seguidas pela falta de avalista/fiador, documentação fiscal exigida, documentação contábil exigida e outros (SEBRAE, 2017).

Embora os empreendedores encontrem outras fontes para financiar a inovação, seja de capital próprio ou de terceiros, ainda existe uma grande dificuldade para conseguir recursos financeiros para seus negócios de cunho inovador (ANDREASSI; SIQUEIRA, 2006). Além
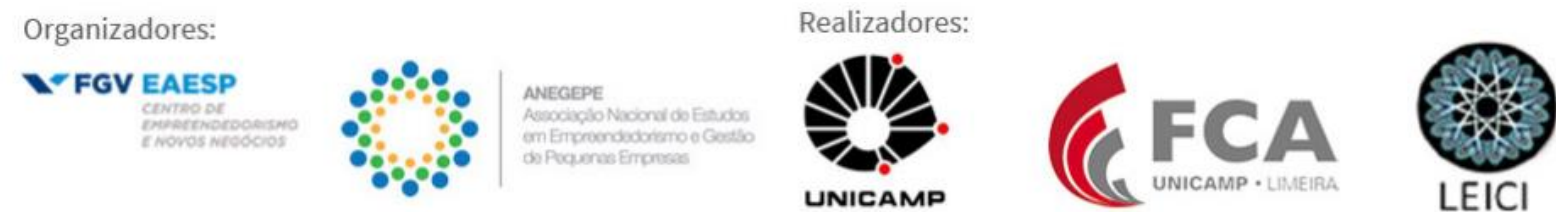
da burocracia, existem as incertezas e os riscos do investimento na fase inicial, que faz com que grande parte das empresas com base tecnológica obtenha recursos financeiros apenas por fontes governamentais (CORDER; SALLES-FILHO, 2006).

Por isso, o governo de diversos países, inclusive o Brasil, tem desenvolvido políticas públicas que promovam programas para financiamento à inovação com o objetivo de apoiar micro e pequenas empresas a considerar atividades inovadoras em sua agenda.

Assim sendo, o objeto de análise das pesquisas que originaram esse artigo é o Programa Tecnova, um instrumento de política pública de inovação, na modalidade de subvenção econômica e que teve como objetivo central apoiar financeiramente os projetos de inovação de micro e pequenas empresas de diversos estados do país. O programa foi escolhido porque utiliza recursos públicos para fomento às empresas e os resultados do mesmo foram divulgados recentemente, durante o ano de 2017, o que possibilita realizar uma análise com dados recentes.

Esse artigo concentra suas análises nos estados do Paraná, Santa Catarina e Rio Grande do Sul, em face da facilidade de acesso aos dados e da proximidade geográfica. Portanto, o objetivo deste estudo consiste em analisar a transparência e a acessibilidade à informação do Programa Tecnova nos estados da região sul. Para tal, foram utilizados os dados de relatórios, documentos públicos e informações disponibilizados pelos órgãos executores dos três estados.

Esse artigo está estruturado em cinco seções: introdução, seguida da revisão da literatura; a terceira contempla a metodologia e a quarta expõem as análises e os resultados encontrados. Por último, as considerações finais contendo os principais achados do estudo.

\section{Referencial Teórico}

A compreensão do tema envolve a fundamentação de financiamento público à inovação, do Programa Tecnova e as formas de avaliar transparência e acessibilidade informação.

\subsection{Financiamento público à inovação}

O financiamento à inovação é fundamental para a alavancagem de investimento, competitividade e sustentabilidade das empresas, embora existam dificuldades de administrar os diferentes interesses (LERNER, 1999; BUENO; TORKOMIAN, 2014). Assim, o Sistema Nacional de Inovação (SNI) deve estar capacitado para "operar de forma compatível e coordenada, de modo a gerar um efeito positivo sobre as expectativas dos agentes principais do sistema, as firmas, e, a partir daí, induzi-las ao aumento do investimento" (MELO, 2008, p. 92).

No Brasil, após várias tentativas focadas nas universidades, o estímulo à atividade inovativa nas empresas por meio de recursos de subvenção econômica iniciou em 2004, quando foi sancionada a Lei da Inovação (Lei no 10.973 de 02/12/2004 e Decreto $n^{\circ} 5.563$ de 11/10/2005) que permitiu, pela primeira vez no país, o apoio público utilizando os recursos de subvenção econômica (BRASIL, 2004).

Este instrumento é operacionalizado pela Financiadora de Estudos e Projetos (FINEP), uma empresa pública vinculada ao Ministério da Ciência, Tecnologia e Inovação (MCTI), que

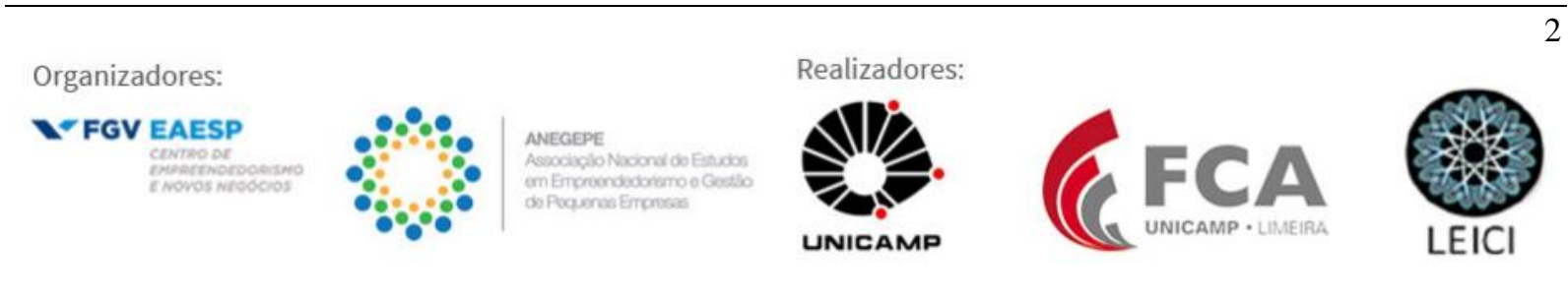


tem recursos oriundos do Fundo Nacional de Desenvolvimento Científico e Tecnológico (FNDCT) e desde 2006 executa a subvenção por meio de chamadas públicas (FINEP, 2017).

Portanto, a subvenção econômica é um tipo de subsídio governamental direcionado a empresas públicas ou privadas, que prioriza as micro e pequenas empresas. Seu objetivo é estimular a inovação tecnológica, compartilhando os custos e riscos inerentes a P\&D (CGEE; ANPEI, 2008; BUENO; TORKOMIAN, 2014; CIRANI et al. 2014) e proporcionando o aumento da competitividade das empresas e da economia do país.

Para ser contemplada por esses recursos, a empresa precisa atender aos critérios estabelecidos na chamada pública e os beneficiários "não precisam fazer a compensação financeira do recurso recebido, isto é, são recursos públicos aplicados a fundo perdido" (MACANEIRO; CHEROBIM, 2009, p. 298). Ou seja, independente do projeto de inovação ter tido sucesso ou não, as empresas contempladas não precisam devolver o recurso ao programa.

Alguns estudos mostram a evolução dos recursos de subvenção (MACANEIRO; CHEROBIM, 2009) e apesar deste ser ainda o menos utilizado pelas empresas segundo a Pesquisa de Inovação (PINTEC) (IBGE, 2016), em 2012 foi criado pela primeira vez o programa Tecnova, objeto de análise desse estudo. O programa surgiu a partir uma parceria entre a FINEP, as Fundações de Amparo à Pesquisa (FAPs) e demais órgãos locais, com o propósito de incentivar a utilização de recursos de maneira integrada, para financiar projetos de inovação de pequenas empresas e fortalecer os sistemas nacionais e regionais de inovação.

O Tecnova é operacionalizado com recursos oriundos da FINEP, dos parceiros estaduais e com a contrapartida das empresas contempladas, o que permite a integração de recursos federais e estaduais. Assim o Tecnova promove a ampliação das operações da FINEP e a consolidação dos sistemas nacionais e regionais de inovação, uma vez que as FAPs de cada estado tem autonomia na elaboração das chamadas públicas.

\subsection{O Programa Tecnova}

As iniciativas que originaram o Programa Tecnova procederam de uma reunião ocorrida em Salvador, em 2004, entre o Fórum Nacional de Secretários Estaduais para Assuntos de Ciência e Tecnologia e o Fórum Nacional das FAPs. O Programa surgiu como forma de ampliar a escala de subvenção econômica e sua origem de fato está registrada no ano de 2012, quando publicou-se o edital da Carta Convite MCTI/ Finep como uma Ação Transversal 01/2012, permitindo que todos os estados brasileiros pudessem submeter suas propostas de participação (FA, 2017).

O objetivo central do programa é motivar micro e pequenas empresas de diversos estados do país a considerar atividades inovadoras em sua agenda, a fim de apoiar os projetos com foco no desenvolvimento de inovações tecnológicas (produtos e/ou processos novos ou aprimorados), que estejam inseridos em temas estratégicos de interesse nacional e estadual. Espera-se desenvolver integração entre o governo, a academia e o setor produtivo, gerando reflexos positivos na economia e na sociedade (FA, 2017).

O resultado da seleção dos parceiros estaduais no âmbito nacional foi anunciado em junho de 2013, partir desse momento as atividades cumpriram cronogramas distintos entre os estados selecionados: os prazos de submissão das propostas, a análise de requisitos formais, a

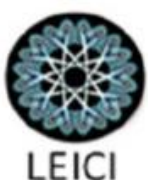


avaliação do mérito e relevância, a interposição, a contratação dos projetos e ao final, a conclusão dos projetos. $\mathrm{O}$ prazo de execução dos projetos era 24 meses para todos.

Foram repassados R $\$ 209,6$ milhões em subvenção econômica, sendo $65 \%$ dos recursos derivados da fonte Finep/MCTI e o restante dos recursos procedentes dos parceiros estaduais. Além desse valor, foi repassado pela FINEP mais R 19 milhões para financiar a infraestrutura e organização dos parceiros estaduais, com o propósito de capacitar os membros envolvidos no programa. Ademais, o Sebrae participou oferecendo R\$ 50 milhões, voltados as atividades de gestão de negócios para empresas selecionadas. Tendo concedido as empresas o valor médio de $\mathrm{R} \$ 366$ mil a cada projeto e como contrapartida, conforme previsto em edital, as empresas realizaram um aporte financeiro correspondente a 5\% (para microempresas) ou 10\% (para empresa de pequeno porte) do valor contemplado (FA, 2017, FINEP, 2017).

A implementação do Tecnova ocorreu em 20 estados do país - Rio Grande do Sul, Santa Catarina, Paraná, Minas Gerais, Rio de Janeiro, Espírito Santo, Paraíba, Alagoas, Pernambuco, Pará, Sergipe, Maranhão, Ceará, Bahia, Mato Grosso, Mato Grosso do Sul, Goiás, Tocantins, Amazonas e Rio Grande do Norte, sendo este último descredenciado durante o período de execução. Portanto, o programa conseguiu abranger $95 \%$ das federações (19 estados) e mobilizou a contratação de 572 projetos.

Como estes são recursos públicos, segundo Corder e Salles-Filho (2006) existe uma pressão social por maior transparência na destinação dos recursos em investimentos para fins econômicos e sociais mais explícitos a sociedade. Desta forma, analisar os impactos e a governança/transparência de um instrumento de política pública é uma maneira de identificar a destinação dos investimentos governamentais e de apresentar à sociedade como os recursos públicos estão sendo destinados ao financiamento à inovação.

Apesar da ampla utilização do instrumento de subvenção econômica em diversos países, os estudos acadêmicos dedicados a avaliar seus resultados são escassos (CARRIJO; BOTELHO, 2013; BORGES; HOFFMANN, 2017). Na literatura brasileira é possível encontrar estudos de fomento à inovação focados em setores específicos, no entanto, existem poucos trabalhos direcionados a instrumentos específicos de fomento à inovação, em especial instrumentos mais recentes (BORGES; HOFFMANN, 2017).

Diante disto, a seção seguinte contempla as questões de transparência e acessibilidade à informação em relatórios públicos.

\subsection{Transparência e acessibilidade à informação em relatórios públicos}

As últimas três décadas demonstraram um grande aumento na tentativa de melhorar aspectos da transparência e da prestação de contas dos governos (COHEN; MAMAKOU; KARATZIMAS, 2017). Aliando-se isso com a praticidade no acesso a informação trazida pela internet temos um cenário onde cada vez mais é exigido dos governos uma maior transparência no que diz respeito a utilização do dinheiro público. Isso é demonstrado pelo crescente número de estudos que buscam analisar questões de governança em relatórios públicos e na prestação de conta de atividades governamentais (JAEGER; BERTOT, 2010; ARMSTRONG, 2011; HARRISON; SAYOGO, 2014; COHEN; MAMAKOU; KARATZIMAS, 2017).

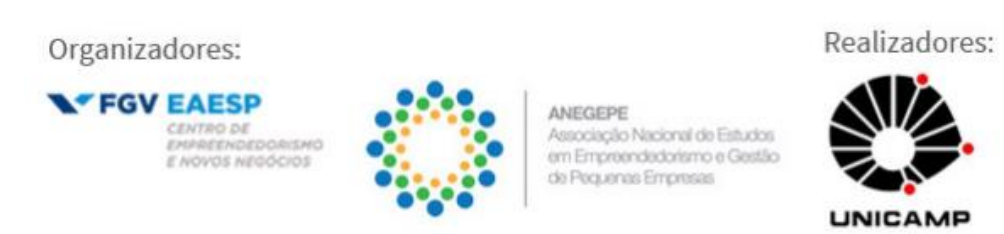

UNICAMP

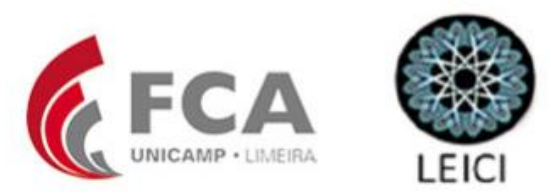


Kierkegaard (2009) salienta que o público tem o direito de ser informado não para a conveniência do governo, mas para a conveniência do próprio público que o governo deve servir. Logo, ao se analisar os estudos que trabalham com questões de acesso a informação governamental, é possível identificar que existe uma concordância de que a internet consiga trazer um maior acesso a tal informação (JAEGER; BERTOT, 2010). Porém, ela também possui problemas que precisam ser remediados e corrigidos, principalmente no que diz respeito a divulgação dos relatórios com resultados e a qualidade da informação fornecida (ARMSTRONG, 2011; HARRISON; SAYOGO, 2014; VILLENEUVE, 2014), a divulgação dos gastos governamentais e da governança adotada (HARRISON; SAYOGO, 2014), a facilidade de acesso a tais informações (JAEGER; BERTOT, 2010; ARMSTRONG, 2011), e a seleção do público alvo que acessará os relatórios de modo as informações serem compreensíveis para eles (COHEN; MAMAKOU; KARATZIMAS, 2017). Tais itens podem ser agrupados então em duas dimensões maiores, sendo elas: (i) transparência; e (ii) acessibilidade à informação.

O presente estudo visa analisar tais itens no que diz respeito às informações sobre o programa Tecnova fornecidas pelos governos dos estados do Paraná, Santa Catarina e Rio Grande do Sul, buscando assim verificar os aspectos de transparência e da acessibilidade à informação sobre tal programa, a partir de informações providas pelos órgãos executores de cada estado.

\section{Metodologia}

A pesquisa segue abordagem qualitativa. Utiliza pesquisa documental e eletrônica, considerados como dados secundários, visto que as informações contidas foram desenvolvidas e disponibilizadas pelas FAPs e demais órgãos envolvidos. Entre os 19 estados participantes do programa foram escolhidos os estados do Paraná, Santa Catarina e Rio Grande do Sul.

Os dados são analisados pela técnica da análise de conteúdo, seguindo as etapas sugeridas por Bardin (2006): codificação, categorização e inferência. As categorias de análise são provenientes de estudos sobre transparência e acessibilidade à informação de relatórios públicos.

O principal fator limitante da pesquisa foi o acesso aos dados com as FAPs. Em tese, como o recurso para o programa Tecnova foi público, todas as FAPs e demais órgãos deveriam disponibilizar as informações, no entanto não há padronização na divulgação.

Assim, o primeiro passo para o desenvolvimento da pesquisa foi buscar os relatórios disponíveis nos websites das FAPs dos estados do PR, SC e RS, as quais disponibilizaram os relatórios finais e parciais do programa e documentos anexos. Na sequência, foi realizada a busca sobre informações do programa sem se utilizar o buscador disponível no endereço eletrônico, a fim de se verificar a facilidade de acesso na informação dos mesmos a partir do corpo do website, como utilizado em outros estudos similares que analisam questões de acesso a informação e transparência (ARMSTRONG, 2011).

$\mathrm{Na}$ apresentação dos resultados, optou-se por descrever os dados por variáveis de análise, comparando os estados PR, RS e SC de acordo com o Quadro 1 abaixo:
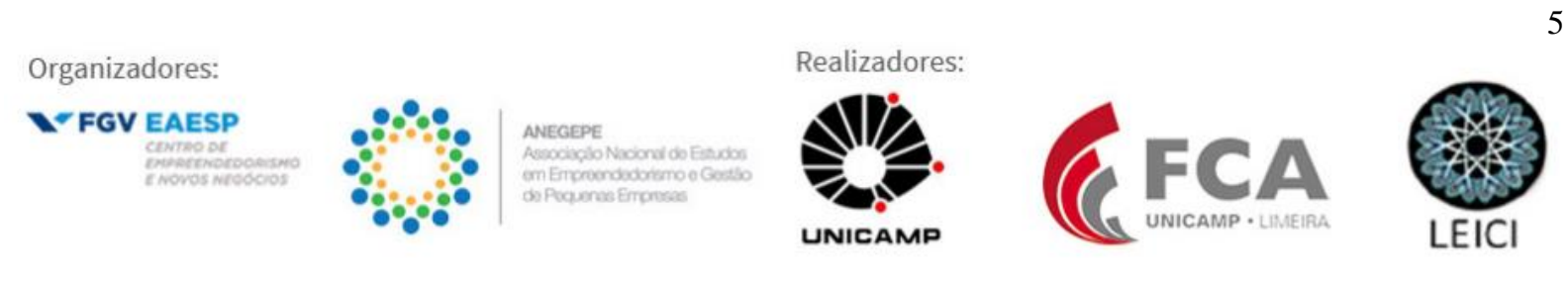
Quadro 1: Dimensões e componentes utilizados na análise

\begin{tabular}{|c|l|l|}
\hline Dimensão & \multicolumn{1}{|c|}{ Componente } & \multicolumn{1}{|c|}{ Autor(es) } \\
\hline \multirow{5}{*}{ Transparência } & Estrutura de governança & Harrison e Sayogo (2014) \\
\cline { 2 - 3 } & Edital de abertura & Elaborado pelos autores \\
\cline { 2 - 3 } & Resultados alcançados & $\begin{array}{l}\text { Armstrong (2011); Harrison e } \\
\text { Sayogo (2014); Villeneuve (2014) }\end{array}$ \\
\cline { 2 - 3 } & $\begin{array}{l}\text { Divulgação e acompanhamento dos gastos } \\
\text { governamentais }\end{array}$ & Harrison e Sayogo (2014) \\
\cline { 2 - 3 } & $\begin{array}{l}\text { Qualidade técnica destas informações: em } \\
\text { relação ao que foi divulgado }\end{array}$ & $\begin{array}{l}\text { Armstrong (2011); Harrison e } \\
\text { Sayogo (2014); Villeneuve (2014) }\end{array}$ \\
\hline \multirow{3}{*}{$\begin{array}{c}\text { Acessibilidade à } \\
\text { informação }\end{array}$} & $\begin{array}{l}\text { Facilidade no acesso as informações } \\
\text { Jaeger; Bertot (2010) e Armstrong } \\
\text { (2011) }\end{array}$ \\
\cline { 2 - 3 } & $\begin{array}{l}\text { Qualidade técnica destas informações: em } \\
\text { relação a como foi divulgado }\end{array}$ & $\begin{array}{l}\text { Armstrong (2011); Harrison e } \\
\text { Sayogo (2014); Villeneuve (2014) }\end{array}$ \\
\hline
\end{tabular}

Fonte: Elaborado pelos autores (2018).

\section{Resultados}

Estão apresentados a seguir os resultados por Estado e as comparações entre eles. A análise contempla dois aspectos principais: a transparência e a acessibilidade à informação.

\subsection{Transparência}

A transparência diz respeito às informações que foram divulgadas pelos órgãos executores, na qual foi analisado especificamente a divulgação da estrutura de governança; edital de abertura; resultados alcançados; divulgação e acompanhamento dos gastos governamentais; e qualidade da informação em relação ao que foi divulgado.

\subsubsection{Divulgação da estrutura de Governança}

No Paraná, a agência de fomento do Tecnova é formada pela Fundação Araucária (FA, 2017) vinculada a Secretaria de Estado da Ciência, Tecnologia e Ensino Superior do Paraná (SETI). Segundo o relatório, a SETI por meio da resolução 43/2013, instituiu dois comitês: Comitê Consultivo e Comitê Financeiro. As atribuições do Comitê Consultivo compreendiam estabelecer e manter os princípios de governança corporativa, aprovar as chamadas públicas e acompanhar periodicamente os resultados do programa. As atribuições do Comitê Financeiro consistem em assessorar o Comitê Consultivo e a própria agência Tecnova-PR no que referese aos aspectos financeiros relacionados ao programa.

A agência de fomento do Tecnova-RS é formada pela Fundação de Amparo à Pesquisa do Estado do Rio Grande do Sul (FAPERGS) (TECNOVA, 2013) vinculada a Secretaria Estadual de Desenvolvimento Econômico, Ciência e Tecnologia (SDECT).

Em Santa Catarina, a agência de fomento do Tecnova-SC é formada pela Fundação de Amparo à Pesquisa do Estado de Santa Catarina (FAPESC, 2013) vinculada a Secretaria do Desenvolvimento Econômico Sustentável (SDS).

Para todos os estados, o órgão concedente foi a FINEP/MCTI, o órgão proponente foram as secretarias vinculadas as agências de fomento, ou seja, no RS foi SDECT, no PR foi SETI e em SC foi SDS. No que diz respeito ao órgão executor principal, no PR foi Fundação Araucária, no RS foi FAPERGS e em SC foi FAPESC. 
O estado do PR foi o único que divulgou informações mais detalhadas sobre sua estrutura de governança, abordando um tópico específico para isso em um dos relatórios finais, o que possibilitou a identificação: as organizações coexecutoras, FIEP e TECPAR; as organizações intervenientes, Reparte e Assespro; as organizações concedentes de recursos financeiros, Governo Federal-MCTI/Finep e Estado do Paraná-SETI; e a unidade gestora e operacional, Agência Tecnova-PR.

No relatório do RS e SC não foram encontrados fluxograma para estrutura organizacional. O que foi possível identificar foi apenas a rede de parceiros no RS, formado por: Badesul, Instituto Euvaldo Lodi (IEL) e a Rede Gaúcha de Incubadoras de Empresas e Parques Tecnológicos (REGINP). E no estado de SC não foram localizadas essas informações mais detalhadas.

Assim, ainda que existam tentativas de melhorar aspectos da transparência e da prestação de contas dos governos (COHEN; MAMAKOU; KARATZIMAS, 2017) e um número crescente de estudos que buscam analisar questões de governança em relatórios e na prestação de conta de atividades governamentais (JAEGER; BERTOT, 2010; ARMSTRONG, 2011; HARRISON; SAYOGO, 2014; COHEN; MAMAKOU; KARATZIMAS, 2017), o estado do PR foi o único que divulgou a estrutura de governança do programa. O estado do RS apresentou de maneira parcial, citando apenas a rede de parceiros formada. E SC foi o estado que menos divulgou a estrutura de governança, uma vez que não foram encontrados as organizações coexecutoras e intervenientes ou mesmo a rede de parceiros.

\subsubsection{Edital de abertura}

Analisando os editais de abertura do programa, obrigatórios para aplicação de recursos públicos, nota-se similaridade na forma de apresentação das informações, porém com diferenças no conteúdo. Os três editais trazem uma descrição do programa e de seus objetivos, de suas áreas apoiadas, dos detalhes de elegibilidade para o programa, dos recursos financeiros a serem concedidos, quais itens podem e não podem ser financiados, do cronograma do programa, dos itens relativos a apresentação da proposta e o conteúdo da mesma, dos itens relativos a questões de contrapartida da empresa, e da execução do projeto pela empresa elegida, sendo estes de caráter obrigatório ao mesmo. As diferenças surgem no que diz respeito a informações adicionais contidas no edital.

Enquanto o edital do estado do Paraná não contempla arquivos em anexo, contendo todas as informações acima citadas em seu corpo, o edital do estado de Santa Catarina contém, além das informações acima mencionadas, um glossário com a definição de itens relevantes do edital junto ao seu corpo, um primeiro anexo com o detalhamento das áreas e temas sendo abordados pelo programa, um segundo anexo com o detalhamento de todas as mesorregiões do estado, e um terceiro anexo com a documentação necessária para a contratação do projeto (sendo este último de informação obrigatória e também contido no edital do estado do Paraná, porém em seu corpo). Já o edital do estado do Rio Grande do Sul é o que mais contempla informações adicionais, contendo além das informações acima citadas seis anexos, sendo eles: (i) Modelo de carta de apresentação da proposta; (ii) Documentação obrigatória para a submissão da proposta; (iii) Três modelos de declarações relacionadas a questões do programa; (iv) Documentação obrigatória para a assinatura do termo de outorga e
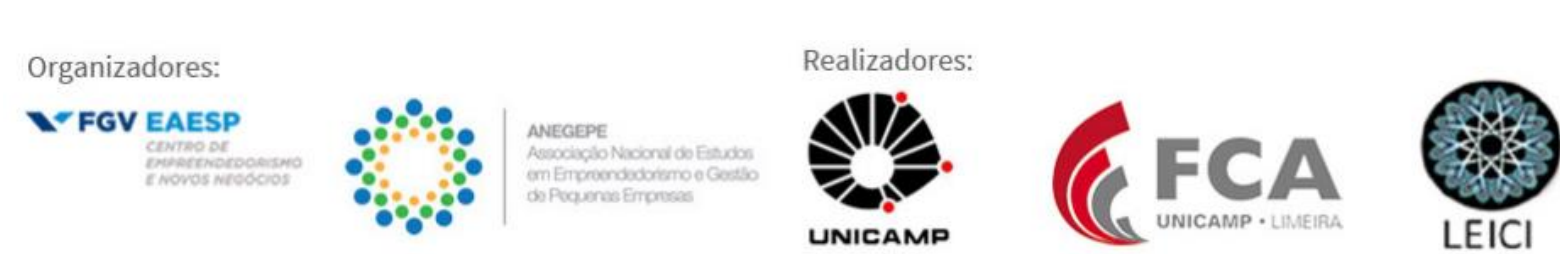
aceitação do auxílio; (v) Detalhamento das áreas e temas; (vi) Termo de outorga e aceitação do auxílio.

Ao se analisar o conteúdo dos editais é possível notar que o estado do Rio Grande do Sul foi o que mais se esforçou em fornecer informações adicionais em seu edital, contendo inclusive modelos de documentos a serem enviados. Todos os editais contam com o fornecimento de canais para se solicitar informações adicionais, porém o edital do Paraná adiciona um item especificamente para isso, o que facilita sua identificação dentro do edital.

Logo, nos editais de abertura não foram encontradas diferenças significativas nas informações apresentadas entre os estados, isso se deve também ao fato de que existe um padrão adotado na elaboração de tais editais.

\subsubsection{Resultados alcançados}

Os resultados dos projetos inovadores podem ser encontrados a curto e a longo prazo, entretanto, como o encerramento do programa ainda é recente, foi possível descrever apenas os resultados de curto prazo, como premiações, patenteamento, registros de marcas e lançamento de novos produtos e/ou processo e limitados aos resultados descritos nos relatórios.

Para o estado do Paraná foram analisados os resultados descritos em dois relatórios, o de "ações e resultados" e "catálogos de produtos". No que diz respeito ao pedido de patentes das soluções inovadoras, das 60 propostas contratadas no PR, 18 delas tem o pedido de patentes depositado no INPI.

Entre as soluções desenvolvidas pelas empresas aportadas no PR, a Solidda Energia afirmou que o projeto alcançou suas metas de desempenho e "a empresa considera que o mesmo foi um sucesso, trazendo benefícios para ela, para os clientes e funcionários, para o meio ambiente e para toda a sociedade".

Os projetos que envolvem desenvolvimento de software não conseguem registrar patentes, por isso empresas do PR como a Corinfo Gestão e Tecnologia realizaram o registro dos domínios, como: www.kekuida.com.br, www.kekuida.com e www.quecuida.com.br. A empresa Oniria também fez o registro de marca, devidamente protocolado no INPI. Outro exemplo foi o projeto da empresa Accion Sistemas para Gestão e Inovação, que gerou o software "Portal da Inovação" auxiliando outras empresas a desenvolverem projetos de inovação, desde a capacitação a ferramentas para gerenciamento. Os resultados das demais empresas contempladas estão descritas no relatório de "catálogos de produtos".

Embora, o documento de "ações e resultados" apresente o tópico "divulgação de resultados", o texto ficou limitado apenas à descrição do evento ocorrido em dezembro de 2016 que apresentou os avanços do programa a um público de 50 participantes convidados. Nesse tópico também foi abordado o evento de encerramento ocorrido em outubro de 2017 cujo objetivo era apresentar à sociedade os resultados alcançados, além da troca de experiências, realização de negócios e distribuição do catálogo das inovações desenvolvidas, entretanto, as informações distribuídas nos eventos não foram descritas formalmente. Portanto, os resultados contidos nos relatórios abrangeram apenas ao desempenho inovador da empresa, como: patentes, registro de marcas, novos produtos e processos comercializados.

Já no estado do Rio Grande do Sul, os resultados do programa foram encontrados nos relatórios gerais de gestão da FAPERGS. No relatório de 2013 foi mencionado o programa

Organizadores:
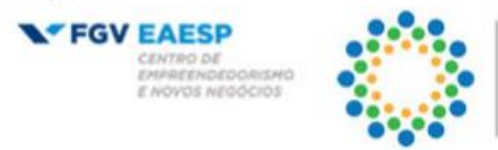

ANEGEPE Avecociagio Naciond do Esudion

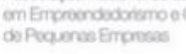

Realizadores:
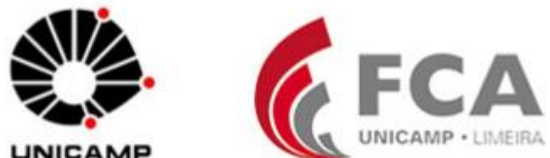

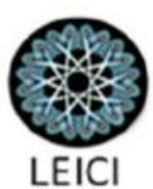


Tecnova e fornecido informações relativas ao total empenhado no mesmo. No relatório de 2014 foram providos maiores detalhes relacionados a quantia empenhada no programa, detalhando a participação de cada instituição que aportou recursos no programa, a distribuição versus a oferta de recursos por tema no programa, a valor das propostas submetidas, enquadradas, recomendadas e contratadas e a quantidade de propostas contratadas por tema de auxílio do programa. No balanço geral dos anos de 2011-2014 foram fornecidas algumas informações também expostas no relatório de 2014 e os detalhes de dois produtos sendo desenvolvidos.

No ano de 2015, o relatório menciona que houve uma visita da FAPERGS a uma empresa que recebeu recursos do programa, e há um destaque para duas empresas participantes, a Agrovec e Eirene Solution, que foram contempladas pelo programa e já haviam lançado produtos inovadores para o agronegócio. A Agrovec utilizou o recurso para financiar o projeto VecAgro 4x4 X-treme, que segundo o engenheiro e sócio da empresa, é mais econômico quando comparado aos concorrentes nacionais e as opções importadas. Além disso, ao longo dos últimos sete anos, o número de funcionários cresceu, de 8 para 19 funcionários e em 2014, a empresa faturou $\mathrm{R} \$ 1,5$ milhão e tinha previsão de continuar mantendo esse faturamento para os próximos anos. O impacto do aporte financeiro, segundo um dos sócios da empresa, auxiliou para que os resultados fossem alcançados de maneira mais rápida, ou seja, "em um ano, obtivemos o resultado de trabalho que levaríamos pelo menos quatro. $\mathrm{O}$ apoio foi a condição para realizarmos o projeto. Buscamos novos horizontes e alcançamos novos mercados".

Por sua vez, a Eirene Solutions desenvolveu o projeto Drone Pulverizador, um aviãorobô que pulveriza plantações com fertilizantes e pesticidas. A partir do recurso financeiro, a empresa conseguiu apresentar um protótipo funcional para testes no final de 2015 e a projeção para 2016 é que o produto substitua os aviões agrícolas e pulverizadores manuais. As vantagens à sociedade podem ser percebidas por meio da comercialização de um produto que não oferece risco a vida, nem contaminação ao piloto, além de ser considerado mais ágil, econômico e menor poder de contaminação ao meio ambiente. O impacto do aporte financeiro do Tecnova, de acordo com o sócio, permite acelerar o crescimento das micro e pequenas empresas, isto significa que se "não houvesse o incentivo, não teríamos capital para contrair pessoas e bancar a infraestrutura necessária para desenvolver um projeto de tecnologia de ponta".

O relatório do ano de 2016 é mais detalhado. Inclui a lista de municípios beneficiados e o segmento de atuação das empresas selecionadas, a demanda apresentada em relação a quantidade de projetos e a distribuição das empresas selecionadas por segmento do programa. O relatório também discute os resultados, a rede de relacionamentos e os detalhes da empresa em questão: nome, produto desenvolvido, número de colaboradores e canais de contato.

Além dos repasses de recursos dos financeiros, as empresas contempladas recebem apoio técnico e acompanhamento dos projetos de inovação. Assim, o programa foi "estruturado com uma rede de parceiros para que, ao final de dois anos... as empresas já tenham alcançado o grau de maturação necessário em seus projetos e tenham condições de seguir em frente com seus empreendimentos".

De acordo o diretor do Tecnova RS, "a maioria já tem condições de estar sozinha no mercado, mas outras ainda precisam de acompanhamento", uma vez que a integração dos
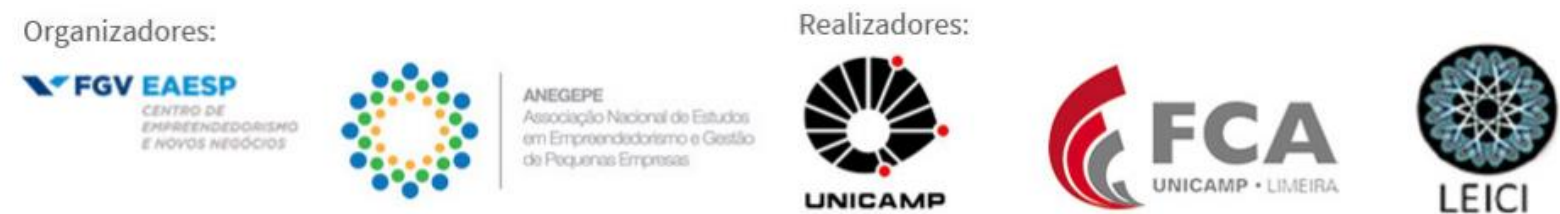
negócios e a formação de parceiros permite que os projetos continuem crescendo, mesmo tendo finalizado o programa. Ele ainda acrescenta que, "é importante fazer com que as ideias sejam transformadas em produtos, processos, gerando empregos e fazendo a economia andar" e por isso um dos principais pontos positivos do programa é o elo entre a academia - seja por parques tecnológicos ou incubadoras - e as empresas, em virtude da oportunidade das ideias saírem do papel. Assim como ele, outros dirigentes envolvidos afirmam a relevância do projeto, corroborando com Godin (2009), que afirma: o processo de inovação no modelo sistêmico envolve diversos atores dentro de três grandes grupos (universidades, empresas e governo), que passam a trabalhar de forma conjunta e em rede.

No que tange ao estado de Santa Catarina, não foram encontrados relatórios tratando especificamente dos resultados do programa, apenas notícias sobre cinco produtos sendo desenvolvidos com auxílio do programa, porém sem maiores informações sobre a estrutura do programa, aporte recebido pelas empresas ou outros detalhes internos relacionados a prestação de contas ou a estrutura de governança do programa.

Assim, ainda que a internet consiga proporcionar maior acesso as informações (JAEGER; BERTOT, 2010), ela pode trazer problemas que precisam ser remediados e corrigidos, principalmente no que diz respeito a divulgação dos relatórios com resultados, e a qualidade da informação fornecida (ARMSTRONG, 2011; HARRISON; SAYOGO, 2014; VILLENEUVE, 2014), como foi possível perceber a diferença das formas de divulgação dos resultados alcançados dos três estados.

\subsubsection{Divulgação e acompanhamento dos gastos governamentais}

Quanto aos recursos governamentais para subvenção econômica, o limite disponibilizado para o Rio Grande do Sul foi de R $\$ 25$ milhões com a seguinte participação: R\$ 15 milhões sendo aportados pela FINEP, vinculada ao Ministério da Ciência, Tecnologia e Inovação (MCTI) e R 10 milhões provenientes da parceria entre o governo do Estado. Para os estados do Paraná e Santa Catarina, ambos os tiveram o limite de recursos governamentais de $\mathrm{R} \$ 22,5$ milhões cada, tendo a participação dividida em $\mathrm{R} \$ 15$ milhões aportados pela FINEP e R \$ 7,5 milhões provenientes dos recursos do estado.

Tais recursos foram direcionados a setores específicos, sendo 3 (três) setores estratégicos de interesse nacional e 5 (cinco) setores prioritários de interesse estadual. Os setores foram Tecnologia da Informação e Comunicação (TIC), Petróleo e gás e Energias alternativas, comum a todos os estados e denominadas como Área Temática Nacional. Além desses três, o RS e o PR também atenderam: Metalmecânico e Automotivo e Agroindustrial. E de maneira particular, o RS ainda atendeu: Saúde Avançada e Medicamentos, Calçados e Artefatos, Indústria Moveleira. O PR atendeu: Mobilidade, Ciências e Tecnologias Ambientais e Ciências Biológicas e Biotecnologia. E SC atendeu: Eletrometalmecânico, Indústria de Móveis e Artefatos de Madeira, Indústria Têxtil e do Vestuário, Indústria de Embalagens e Cadeia Produtiva de Alimentos.

No âmbito nacional, o programa recebeu o total de 1859 projetos, atingindo $212 \%$ da meta total estipulada pelo programa, que era 876 projetos. A meta de contratação para os estados era de 75 projetos em cada. O Paraná foi o estado que mais recebeu propostas, tendo recebido 219 propostas e 60 projetos foram contratados totalizando $\mathrm{R} \$ 18,77$ milhões em recursos de subvenção econômica. No Rio Grande do Sul, foram recebidas 206 propostas e 50
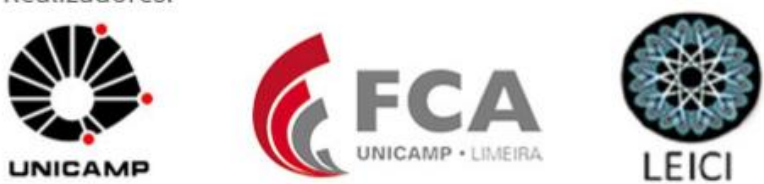
projetos foram contratadas pelo programa totalizando $\mathrm{R} \$ 22,4$ milhões. E em Santa Catarina, 210 propostas foram recebidas e 53 projetos foram contratados, entretanto, não foi localizado o montante total direcionado.

A cerca do valor concedido as empresas, no RS o valor variou entre $\mathrm{R} \$ 200$ mil e $\mathrm{R} \$$ 667 mil reais. No PR e em SC os valores ficaram entre R\$ 180 mil e R\$ 600 mil.

\subsubsection{Qualidade da informação: em relação ao que foi fornecido}

Em relação ao que foi disponibilizado de informação, pode-se observar que o Paraná apresentou a maior transparência dos três estados, divulgando desde uma lista com todos os projetos desenvolvidos pelas empresas aportadas (intitulada "catálogo de produtos") e um segundo documento com a prestação de conta (intitulado "ações e resultados").

Por outro lado, no estado de Santa Catarina não foram encontrados relatórios tratando especificamente dos resultados do programa. No website da organização executora do estado foram encontradas apenas as notícias e o edital de abertura e nenhuma informação relacionada à estrutura de governança, resultados obtidos ou gastos governamentais.

Já no estado do Rio Grande do Sul, foram encontrados os resultados parciais e informações a cerca do programa nos relatórios de gestão anual da FAPERGS, referente ao período de 2011-2014, 2014, 2015 e 2016.

Pode-se observar então que a qualidade em relação ao que foi disponibilizado de informação sobre o programa, os estados do Paraná e Rio Grande do Sul se destacaram do estado Santa Catarina, pois apresentaram maiores informações sobre o mesmo.

\subsection{Acessibilidade à informação}

A acessibilidade à informação refere-se à facilidade de acesso às informações a cerca do programa e a qualidade técnica em relação a como foi fornecido a partir do corpo dos websites.

\subsubsection{Facilidade no acesso as informações}

A facilidade de acesso foi avaliada na prática, ao pesquisar os websites das entidades executoras de cada estado, sem a utilização de buscadores disponíveis nos endereços eletrônicos em questão.

Para o estado do Paraná, o website da Fundação Araucária foi o analisado. Neste as informações do programa Tecnova foram encontradas com relativa facilidade. Ao clicar na aba lateral "chamadas e projetos" já é possível encontrar um item específico intitulado "tecnova". Em seguida, o usuário é redirecionado para a página do programa Tecnova no estado do Paraná, a qual contempla um resumo do programa no Estado, além dos documentos relacionados ao programa e as informações da agência operacional do programa Tecnova-PR, com endereço, telefone e e-mail e os nomes dos membros da equipe do programa nos anos de 2013-2017. Além disso, também foi criado um website para o programa, mas este trazia informações apenas sobre o evento de encerramento do programa.

Para o estado de Santa Catarina, o website da FAPESC foi o analisado. As informações do Tecnova foram encontradas após se clicar na aba "chamadas públicas". Após se clicar no item, foi encontrado o seguinte edital: 2013 | EDITAL DE CHAMADA PÚBLICA FAPESC No 03/2013 e logo após, o website foi redirecionado para a página do
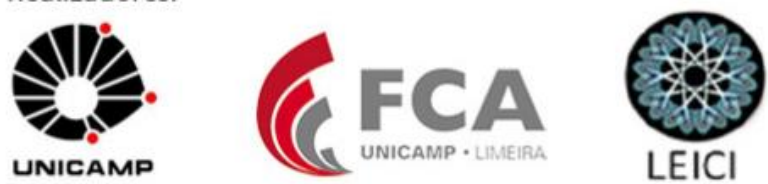
Tecnova-SC contendo as informações sobre edital. Embora as propostas tivessem um prazo de execução de até no máximo 24 meses, contando a data de publicação do contrato de subvenção no Diário Oficial do Estado (DOE), após a análise de acessibilidade, não foram encontradas informações sobre o encerramento, mesmo sendo este o primeiro estado a lançar o Tecnova no país. Assim, ao se analisar o edital, a contratação dos projetos ocorreu em 01/04/2014 (inicialmente ocorreria em 15/02/2014 e sendo posteriormente prorrogado para essa nova data) e após quase dois anos depois do término do prazo de execução (que deveria ocorrer em 01/04/2016) não foram encontrados relatórios de resultados e nem informações a cerca do evento de encerramento, apenas algumas notícias relativas a criação de produtos a partir do financiamento do programa Tecnova. O último documento encontrado foi o "2013 | EDITAL DE CHAMADA PÚBLICA FAPESC N 03/2013” e nenhuma outra informação sobre o encerramento foi encontrada.

Para o estado do Rio Grande do Sul, o website da FAPERGS foi o analisado. As informações do programa Tecnova foram encontradas após se clicar na aba "auxílios" e em seguida na opção "formas de apoio". Após isso, foi necessário clicar no item "editais" (sendo estes classificados por ano de lançamento). Depois, foi selecionado o "ano" de lançamento do programa Tecnova (2013). Após tal procedimento, foi encontrada a página do edital de abertura do programa, e ao clicar, a página era redirecionada para outro website (www.tecnova.rs.gov.br) contendo os principais documentos sobre o programa. Tal website funciona como um repositório de informações sobre o programa, contendo as notícias relacionadas ao mesmo, os parceiros do programa, o edital e os arquivos relacionados ao mesmo, além de uma lista de perguntas frequentes e downloads com informações complementares relevantes para o programa, uma lista com todas as empresas participantes, o cronograma, um canal para se comunicar com o órgão executor do programa e algumas informações adicionais sobre o programa Tecnova no estado.

Assim, considerando as questões de facilidade de acesso à informação, o website da Fundação Araucária foi o mais acessível, pois com apenas dois cliques o usuário consegue chegar a página contendo todas as informações do programa, corroborando os argumentos de Jaeger e Bertot (2010) e Armstrong (2011) que a facilidade de acesso pode contribuir na transparência do instrumento de políticas públicas.

O website de Santa Catarina apesar de possuir um local com suas chamadas públicas, não possui a divisão das chamadas por ano, apenas com a ordenação delas em ordem decrescente. Na página da FAPESC, na aba "chamadas públicas" são exibidos dez resultados por página, o que faz com que a busca seja um pouco mais extensa, pois não se sabe ao certo em qual página estão os resultados de determinado ano. Além disso, tais chamadas normalmente não contemplam o nome do programa referente a chamada em questão no seu título, sendo o nome apenas encontrado na breve descrição da chamada, que fica abaixo do título. Assim, tal situação pode dificultar um pouco mais o acesso as informações do programa.

$\mathrm{O}$ acesso ao website do estado do Rio Grande do Sul é mais complicado que o do Paraná e relativamente mais fácil que o de Santa Catarina. Assim, de modo semelhante ao website do estado Paraná, o os editais são divididos por anos, o que facilita a localização de um edital relacionado ao ano específico, porém como não está nomeado no formato de chamada pública (o que normalmente é o padrão para tal tipo de edital) a localização foi um
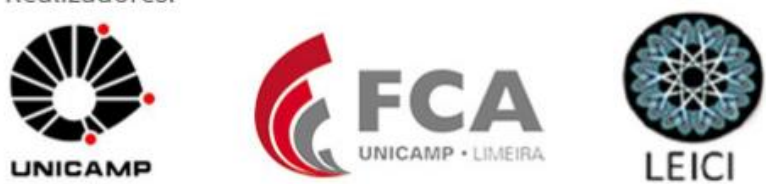
pouco mais dificultosa. Tal cenário é compensado pelo fato de que o estado ter criado um website para o programa Tecnova, o que facilita e faz com que todas as informações se concentrem em um sítio específico na internet. Isso provavelmente faz com que ao se pesquisar em buscadores da internet sobre o programa no estado, tal website seja o primeiro resultado, já contendo todas as informações do mesmo. Outro ponto relevante é o de que o website do programa em questão contempla as notícias do programa, o que facilita o acesso a informações adicionais.

\subsubsection{Qualidade da informação: em relação a como foi fornecido}

Em relação a como tais informações foram apresentadas, mais uma vez o estado do Paraná apresenta maior vantagem em relação aos demais estados, pois concentra as suas informações em um único lugar, mais precisamente todas elas podem ser encontradas em dois relatórios no mesmo sítio eletrônico, um contento o catálogo de produtos desenvolvidos e um segundo contendo os resultados e ações do programa.

O estado do Rio Grande do Sul apresenta informações relacionadas aos resultados do programa, no entanto, elas encontram-se espalhadas em diversos sítios, no caso nos relatórios anuais do estado, não sendo feita menção que os resultados do programa poderiam ser encontrados lá. Apesar de tal estado ter criado um website específico para o Tecnova, não foram localizadas as informações específicas relacionadas aos resultados do programa, exceto por algumas notícias sobre os produtos que foram desenvolvidos.

E em relação ao estado de Santa Catarina, como tal estado não apresentou relatórios específicos sobre os resultados, este item não foi possível ser avaliado.

\section{Conclusão}

Para cumprir seu objetivo, o estudo avaliou sete componentes: estrutura de governança; edital de abertura; resultados alcançados; divulgação e acompanhamentos dos gastos governamentais; qualidade técnica em relação ao que foi divulgado; facilidade no acesso as informações; e qualidade técnica em relação a como tais informações foram disponibilizadas.

A estrutura de governança foi apresentada de maneira distinta nos três estados. No que diz respeito ao edital de abertura, a similaridade foi encontrada nas descrições das informações principais do edital e as diferenças surgem no que tange as informações adicionais contidas no edital.

Quanto aos resultados alcançados foram encontrados apenas os resultados de curto prazo. Os resultados do desempenho da organização e dos aspectos da cadeia produtiva, que impactam diretamente à sociedade, não foram encontrados em nenhum dos relatórios.

No que tange a divulgação e acompanhamento dos gastos governamentais, o montante disponibilizado e repassado aos estados foram divulgados nos relatórios e nos websites dos três estados. Também foram divulgados os setores estratégicos que tais recursos foram direcionados, tanto de interesse nacional quanto os de interesse estadual. E por último, ainda em relação à dimensão transparência, a qualidade técnica em relação ao que foi disponibilizado de informação, os estados do Paraná e Rio Grande do Sul se destacaram do estado Santa Catarina, pois apresentaram maiores informações sobre o mesmo.

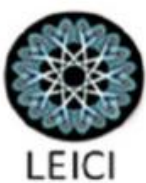


Em relação a acessibilidade à informação, o presente trabalho avaliou dois componentes: facilidade no acesso as informações e qualidade técnica destas informações em relação a como tal informação foi apresentada. Em relação à primeira, no estado Paraná o website da Fundação Araucária apresentou maior facilidade para se chegar as informações do Tecnova. Enquanto que o estado do Rio Grande do Sul criou um website exclusivo para o programa e por último, Santa Catarina foi o estado que apresentou maior dificuldade no acesso as informações.

Quanto à qualidade técnica destas informações o estado do Paraná concentra todas as informações em dois relatórios, no mesmo sítio eletrônico. Já o Rio Grande do Sul as informações estão espalhadas em diversos sítios e de forma desagregada nos relatórios de gestão anual da FAPERGS. E em relação ao estado de Santa Catarina, como tal estado não apresentou relatórios específicos sobre os resultados, este item não foi possível ser avaliado.

Portanto, pode-se concluir que a transparência e a acessibilidade às informações do programa Tecnova, foi mais significativo no estado do Paraná, seguidos pelo Rio Grande do Sul e Santa Catarina. Esse resultado colabora para o aprimoramento do instrumento de política pública direcionado a micro e pequenas empresas inovadoras nos diversos estados e apresenta a sociedade como os recursos públicos estão sendo utilizados.

Sugere-se como pesquisa futura a investigação sobre o desempenho das micro e pequenas empresas inovadoras e os impactos na cadeia produtiva, após o aporte financeiro das empresas contempladas. Outra sugestão, é ampliar o estudo para os demais estados contemplados pelo programa. O principal fator limitante da pesquisa é o acesso apenas aos dados secundários das FAPs, como cada estado possui um órgão executor diferente, as informações do programa contidas nos relatórios e documentos são distintas e grande parte não é padronizada.

\section{Referências}

ANDREASSI, T.; SIQUEIRA, E. M. R. The funding of new technology-based firms in Brazil. International Journal Entrepreneurship and Innovation Management, v. 6, n. 4/5, 2006.

ARMSTRONG, C. Providing a clearer view: An examination of transparency on local government websites. Government Information Quarterly, v. 28, p. 11-16, 2011.

BARDIN, L. Análise de conteúdo. Lisboa: Edições 70, 2006.

BORGES, D. B.; HOFFMANN, M. G. A Subvenção Econômica como instrumento de fomento à inovação: análise sob a perspectiva de empresas de TIC da Grande Florianópolis. Revista Brasileira de Gestão e Inovação, v. 5, n. 1, 2017.

BRASIL. Lei no 10.973, de 2 de dezembro de 2004. Dispõe sobre incentivos à inovação e à pesquisa científica e tecnológica no ambiente produtivo e dá outras providências. Lex: Coletânea de Legislação e Jurisprudência, São Paulo, p. 2. Disponível em: 
<http://www.planalto.gov.br/ccivil_03/_ato2004-2006/2004/lei/110.973.htm>. Acesso em: 15 dez. 2017.

BUENO, A.; TORKOMIAN, A. L. V. Financiamentos à inovação tecnológica: reembolsáveis, não reembolsáveis e incentivos fiscais. Revista de Administração e Inovação, v. 11, n. 4, p. 135-158, 2014.

CARRIJO, M. C.; BOTELHO, M. R. A. Cooperação e inovação: uma análise dos resultados do Programa de Apoio à Pesquisa em Empresas (Pappe). Revista Brasileira de Inovação, v. 12, n. 2, p. 417-448, 2013.

CGEE; ANPEI. Os novos instrumentos de apoio à inovação: uma avaliação inicial. Brasília: Centro de Gestão e Estudos Estratégicos - Associação Nacional de Pesquisas e Desenvolvimento, 2008. Disponível em <http://www.cgee.org.br/publicacoes/nov_instr_inov.php>. Acesso: 27 de nov de 2017.

CIRANI, C. B. S.; JESUS, M. A. S.; ESTEVES, G. B; SOUSA, V. J. Use of Policies for Innovation in Brazilian Enterprises of São Paulo State. Latin American Business Review, v. 15, p. 45-64, 2014.

COHEN, S; MAMAKOU, X. J; KARATZIMAS, S. IT-enhanced popular reports: Analyzing citizen preferences. Government Information Quarterly, v.34, n.2, p. 283-624, 2017.

CORDER; S.; SALLES-FILHO, S. Aspectos Conceituais do Financiamento à Inovação. Revista Brasileira de Inovação, v. 5, n. 1, 2006.

FINEP - Financiadora de Estudos e Projetos. Tecnova, 2017. Disponível em: $<$ http://www.finep.gov.br/apoio-e-financiamento-externa/programas-elinhas/descentralizacao/tecnova>. Acesso 17 dez. 2017.

FAPESC - Fundação de Amparo à Pesquisa e Inovação do Estado de Santa Catarina. Edital de Chamada Pública FAPESC nº 03/2013, 2013b. Disponível:

$<$ http://www.fapesc.sc.gov.br/files/chamada2013/edital_tecnova_sc_final_com_anexos.pdf $>$. Acesso em: 20 jan. de 2018.

FA - FUNDAÇÃO ARAUCÁRIA . Projeto Tecnova-PR, 2017. Disponível:

$<$ http://www.fappr.pr.gov.br/modules/conteudo/conteudo.php?conteudo=108 $>$. Acesso em: 20 jan. de 2018.

GODIN, B. T. Making science, technology and innovation policy: Conceptual frameworks as narratives. Review Innovation RICEC, 1(1), 1-23, 2009. 
HARRISON, T. T; SAYOGO, D. S. Transparency, participation, and accountability practices in open government: A comparative study. Government Information Quarterly, v.31. n.4, p.513-525, 2014.

IBGE - Instituto Brasileiro de Geografia e Estatística. Pesquisa de Inovação - 2014, 2016. Disponível em: <https://ww2.ibge.gov.br/home/estatistica/economia/industria/pintec/2014/default.shtm>. Acesso em: 17 dez. 2017.

JAEGER, P. T; BERTOT, J. C. Transparency and technological change: Ensuring equal and sustained public access to government information. Government Information Quarterly, v. 27. p.371-376, 2010.

KIERKGAARD, S. Open access to public documents - More secrecy, less transparency. Computer Law \& Security Review, v.25, p.3-27, 2009.

LERNER, J. The Government as Venture Capitalist: The Long-Run Impact of the SBIR Program. The Journal of Business, v. 72, n. 3, p. 285-318, 1999.

MACANEIRO; M. B.; CHEROBIM, A. P. M. O financiamento da inovação tecnológica por meio de programas governamentais de apoio às empresas brasileiras. RACE, Unoesc, v. 8, n. 2, p. 291-324, 2009.

MELO, L. M. Financiamento à Inovação no Brasil: análise da aplicação dos recursos do Fundo Nacional de Desenvolvimento Científico e Tecnológico (FNDCT) e da Financiadora de Estudos e Projetos (FINEP) de 1967 a 2006. Revista Brasileira de Inovação, v. 8, n. 1, p. 87-120, 2009.

PEREZ, C. Financiai bubbles, crises and role of government in unleashing golden ages. Working Paper. FINNOV, Reino Unido, 2012.

SEBRAE - Serviço Brasileiro de Apoio às Micro e Pequenas Empresas. O Financiamento das MPE no Brasil, 2017. Disponível em: <http://datasebrae.com.br/wpcontent/uploads/2017/09/RELAT\%C3\%93RIO-ESPECIAL-Financiamento-das-MPE-2017Final.pdf $>$. Acesso em 20 jan. 2018.

TECNOVA-RS. Edital FAPERGS 16/2013, 2013. Disponível: <http://www.tecnova.rs.gov.br/manuais/Edital_2013_16_tecnova_RS.pdf $>$. Acesso em: 20 jan. 2018.

VILLENEUVE, J. P. Transparency of Transparency: The pro-active disclosure of the rules governing Access to Information as a gauge of organizational cultural transformation. The case of the Swiss transparency regime. Government Information Quarterly, v.31, n.4, p.556-562, 2014.
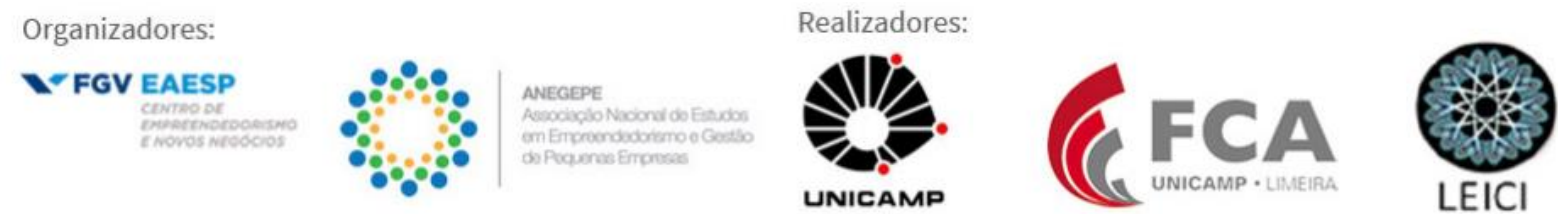